\section{FEATURE}

Ian Richardson

\section{Office for National Statistics}

\section{SUMMARY}

The experimental services producer price index (SPPI) measures movements in prices charged for services supplied by businesses to other businesses, local and national government. This article shows the effects some industries are having on the top-level SPPI. It continues the quarterly feature previously published in Economic Trends. The data produced are used internally by the Office for National Statistics as a deflator for the Index of Services and the quarterly measurement of gross domestic product. The index is also used by HM Treasury and the Bank of England to help monitor inflation in the economy.

\title{
Services producer price index (experimental) - third quarter 2007
}

D rices of business-to-business services rose by 2.6 per cent in the year to the third quarter of 2007. This is based on a comparison of the change in the top-level services producer price index (SPPI) on the net sector basis.

Figure 1 shows how the percentage change for the top-level SPPI (net sector) compares with the retail prices index (RPI) all services sector, and the producer price index (PPI) for all manufactured goods (net sector).

The top-level results, on both gross and net sector bases, are shown in Table 1. In 2007 Q3, the top-level SPPI (net sector) rose by 0.4 per cent compared with the previous quarter.

Figure 2 depicts the SPPI annual growths

Figure 1

Experimental top-level SPPI compared with the RPI and PPI

Percentage change, quarter on same quarter a year earlier

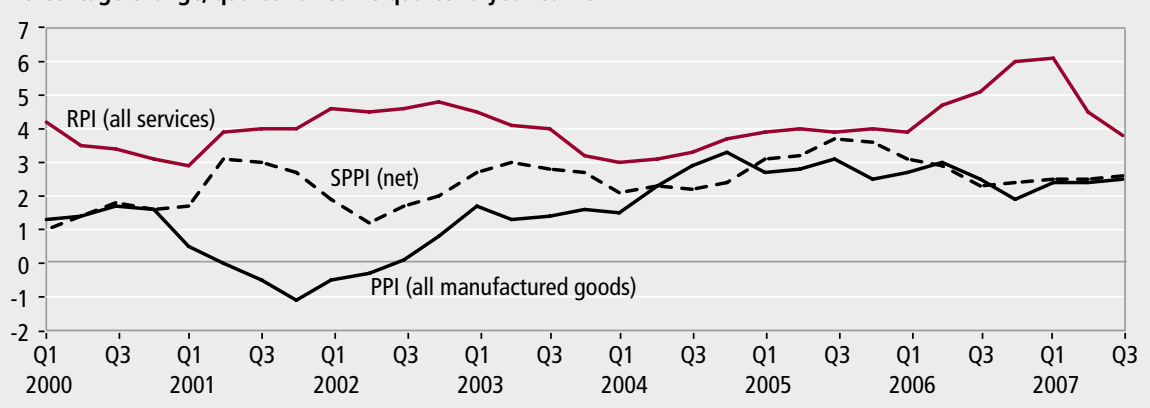

Figure 2

Experimental top-level SPPI

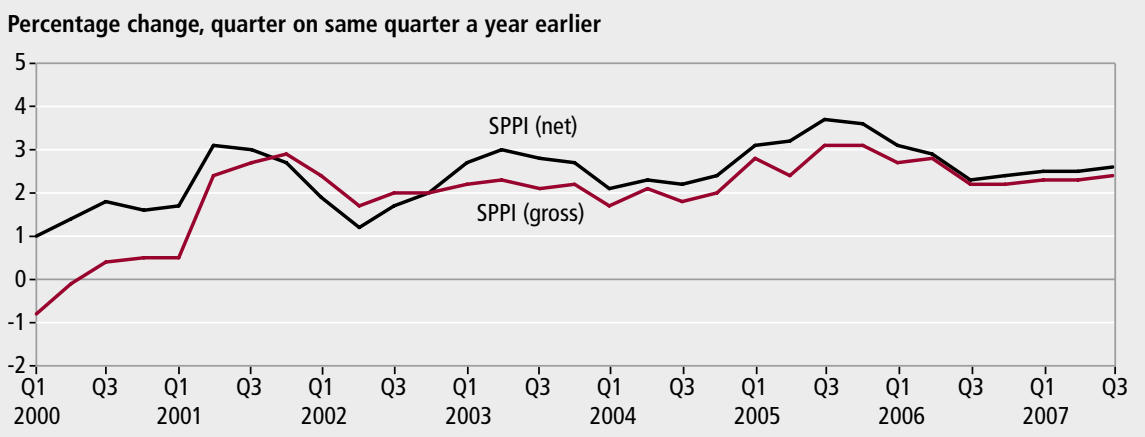


Table 1

Top-level SPPI results

\begin{tabular}{|c|c|c|c|c|}
\hline & \multicolumn{2}{|c|}{ SPPI quarterly index values, $2000=100$} & \multicolumn{2}{|c|}{$\begin{array}{c}\text { Percentage change, quarter on same } \\
\text { quarter a year earlier }\end{array}$} \\
\hline & Gross sector & Net sector & Gross sector & Net sector \\
\hline 2000 Q1 & 100.1 & 99.7 & -0.8 & 1.0 \\
\hline 2000 Q2 & 99.9 & 99.8 & -0.1 & 1.4 \\
\hline 2000 Q3 & 99.9 & 100.1 & 0.4 & 1.8 \\
\hline 2000 Q4 & 100.1 & 100.5 & 0.5 & 1.6 \\
\hline 2001 Q1 & 100.6 & 101.3 & 0.5 & 1.7 \\
\hline 2001 Q2 & 102.3 & 102.9 & 2.4 & 3.1 \\
\hline 2001 Q3 & 102.7 & 103.1 & 2.7 & 3.0 \\
\hline 2001 Q4 & 102.9 & 103.2 & 2.9 & 2.7 \\
\hline 2002 Q1 & 103.1 & 103.2 & 2.4 & 1.9 \\
\hline 2002 Q2 & 104.1 & 104.2 & 1.7 & 1.2 \\
\hline 2002 Q3 & 104.8 & 104.8 & 2.0 & 1.7 \\
\hline 2002 Q4 & 105.0 & 105.3 & 2.0 & 2.0 \\
\hline 2003 Q1 & 105.3 & 106.0 & 2.2 & 2.7 \\
\hline 2003 Q2 & 106.5 & 107.3 & 2.3 & 3.0 \\
\hline 2003 Q3 & 106.9 & 107.8 & 2.1 & 2.8 \\
\hline 2003 Q4 & 107.3 & 108.2 & 2.2 & 2.7 \\
\hline 2004 Q1 & 107.1 & 108.2 & 1.7 & 2.1 \\
\hline 2004 Q2 & 108.7 & 109.8 & 2.1 & 2.3 \\
\hline 2004 Q3 & 108.9 & 110.1 & 1.8 & 2.2 \\
\hline 2004 Q4 & 109.4 & 110.8 & 2.0 & 2.4 \\
\hline 2005 Q1 & 110.1 & 111.6 & 2.8 & 3.1 \\
\hline 2005 Q2 & 111.3 & 113.3 & 2.4 & 3.2 \\
\hline 2005 Q3 & 112.2 & 114.3 & 3.1 & 3.7 \\
\hline 2005 Q4 & 112.8 & 114.8 & 3.1 & 3.6 \\
\hline 2006 Q1 & 113.1 & 115.1 & 2.7 & 3.1 \\
\hline 2006 Q2 & 114.4 & 116.6 & 2.8 & 2.9 \\
\hline 2006 Q3 & 114.7 & 116.9 & 2.2 & 2.3 \\
\hline 2006 Q4 & 115.3 & 117.6 & 2.2 & 2.4 \\
\hline 2007 Q1 & 115.7 & 118.0 & 2.3 & 2.5 \\
\hline 2007 Q2 & 117.0 & 119.4 & 2.3 & 2.5 \\
\hline 2007 Q3 & 117.4 & 119.9 & 2.4 & 2.6 \\
\hline
\end{tabular}

for both the net and gross sector time series. The annual growth for the SPPI net sector rose to 2.6 per cent in $2007 \mathrm{Q} 3$, up from 2.5 per cent in 2007 Q2. The gross SPPI growth at 0.3 per cent in 2007 Q3 was down from 1.2 per cent in the previous quarter. The difference in the annual growth between the gross and net sector SPPI was 0.2 percentage points this quarter.

\section{Industry-specific indices}

Tables available on the National Statistics website contain the data for the 33 industries for which indices of services producer prices are currently available. The weights for each industry index are shown at both gross and net sector levels. Comparing Q3 2007 with Q3 2006, some key points to note are:

- property rentals rose 4.7 per cent, due to sustained growth within the sector as reported by the Investment Property Databank
- $\quad$ sewerage services prices rose by 6.5 per cent, following rises reported by OFWAT. These are updated on an annual basis in Q2

- freight transport by road rose by 1.3 per cent, due to annual increases taking into account the rising costs of overheads, for example, the cost of fuel

- employment agency activities rose by 2.8 per cent, due to supply and demand for staff

\section{Next results}

The next set of SPPI results will be issued on 27 February 2008 on the National Statistics website at www.statistics.gov.uk/sppi

\section{Further information}

All SPPI tables and articles on the methodology and impact of rebasing the SPPI and the redevelopment of an index for business telecommunications (together with more general information on the SPPI) are available at

www.statistics.gov.uk/sppi

A summary quality report for the SPPI can be found at

www.statistics.gov.uk/about/data/ methodology/quality/information business_statistics.asp

\section{CONTACT}

凶elmr@ons.gsi.gov.uk 


\section{TECHNICAL NOTE}

1 The experimental services producer price index (SPPI) replaces the former corporate services price index (CSPI). It measures movements in prices charged for services supplied by businesses to other businesses, local and national government. It is not classified as a National Statistic.

2 Unless otherwise stated, index numbers shown in the main text are on a net sector basis. These relate only to transactions between the corporate services sector and other sectors. Detailed tables available on the National Statistics website also contain gross sector indices which include transactions within the corporate services sector.

3 Indices relate to average prices per quarter. The full effect of a price change occurring within a quarter will only be reflected in the index for the following quarter. All index numbers exclude VAT and are not seasonally adjusted.

4 SPPI inflation is the percentage change in the net sector index for the latest quarter compared with the corresponding quarter in the previous year.

5 Grants from the European Commission helped ONS to begin developing the SPPI. Funding of approximately 600,000 euros was awarded between 2002 and 2005. This has now ceased.

6 A number of external data sources are currently used in the compilation of the SPPI, as follows:

Investment Property Database (IPD) - property rental payments

Office of Communications (Ofcom) - business telecommunications

Office of Water Services (OFWAT) - sewerage services

Parcelforce - national post parcels

Office of Rail Regulation (ORR) - business rail fares 